\title{
The Ability of Fishes to Extract Oxygen at Different Hydrogen Ion Concentrations of the Medium.
}

\author{
By \\ Hem Singh Pruthi, M.Sc.(Punjab), Ph.D (Cantab). \\ Assistant Superintendent, Zoological Survey of India ; Fellow, International \\ Education Boxrd.
}

(From the Marine Biological Laboratory, Plymouth.)

Powers, * working on some marine fishes, arrived at the important conclusion that the ability of fishes to absorb oxygen at low pressures is more or less dependent upon the hydrogen ion concentration of the water. His method of research was briefly as follows : a fish was placed in a two-quart jar filled with water, which was closed airtight with a rubber stopper. The $\mathrm{pH}$ and the oxygen determinations were made immediately after all the movements of the fish had ceased. The amount of oxygen left at death represented, according to Powers, the pressure below which the fish at the particular $\mathrm{pH}$ could not extract any more oxygen from water. Powers did not control the amount of oxygen at the beginning of an experiment; he says, "it was always sufficiently high so that the fish did not at first suffer from oxygen want."

While working recently on the influence of some physical and chemical conditions of water on May-fly larvæ, I observed that the amount of oxygen which was left at death at a particular $\mathrm{pH}$ depended on the amount of oxygen which was originally present in the water ; for instance, if at $\mathrm{pH} 4 \cdot 0$, starting with 6 c.c. per litre of oxygen, 3 c.c. per litre was left, only 1.0 c.c. was left if the original amount was 4.0 c.c. per litre. If in the first case the larvæ at the concentration of 3 c.c. per litre died for lack of ability to absorb any more oxygen, as Powers' conclusions will warrant us to assume, in the second case also the individuals should have died when that tension was reached. Moreover, it was noticed that the time for which the larvæ lived in two waters having the same $\mathrm{pH}$ but different amounts of oxygen was almost the same. This strongly suggested that the larvæ died, not on account of the fact that they could not at that $\mathrm{pH}$ extract any more oxygen at the particular pressure, but due to some other cause, presumably the direct influence of the hydrogen ions.

$$
\text { * Journ. Gen. P.iys., IV, p. } 305 .
$$


As this point is of great physiological importance, to verify the above hypothesis a fish, Gasterosteus aculeatus, the common "stickleback," was chosen for detailed experiments, which are reported below :-

The most crucial test by which Powers could have tested his results and their interpretation was to observe on a fresh fish the effect of the water in which one had died previously, presumably on account of the fact that it could not absorb oxygen at that pressure, i.e. for instance, if the herring, Clupea, was observed to die at $\mathrm{pH} 7 \cdot 1$, leaving $2 \cdot 5$ c.c. per litre of oxygen, before concluding that Clupea at $\mathrm{pH} 7 \cdot 1$ cannot extract oxygen below 2.5 c.c. per litre concentration, Powers should have put another herring in the same water to see whether the fish died in a short time, which it should have done if his view was correct. Powers did not test his conclusion in this manner.

In the case of sticklebacks I have performed a long series of experiments on these lines, which are detailed in Tables 1-5 (p. 744). The $\mathrm{pH}$ of water was varied by adding small amounts of dilute $\mathrm{HCl}$. Under Column I of the tables is given the time for which the first lot of stickles lived at a particular $\mathrm{pH}$. Under Column $\mathrm{II}$ is given the time for which the second lot lived when put in the same waters in which the first lot had died. The mouth of the jar was opened, fresh specimens introduced, and the mouth was closed again as quickly as possible. As many as six lots were introduced in some jars in this way. An inspection of the tables will show that, contrary to what one would expect from the conclusions of Powers, the fish of the successive lots lived for almost the same time. If the first lot had died because it could no longer extract oxygen at that pressure, the second when introduced in the same waters should have died within a short time, and the third in any case should have done so at once.

It may be added that in all the above experiments the $\mathrm{pH}$ and oxygen content were checked before starting a fresh lot; the jars opened for this purpose were, of course, not used during the rest of the series. Moreover, on account of the fact that the fish as a product of respiration added some $\mathrm{CO}_{2}$ to the water, the $\mathrm{pH}$ at the beginning of a fresh lot would be slightly lower than that at the start of a previous one, but the specimens being small $(0 \cdot 20-1 \cdot 5 \mathrm{gm}$.) and the experimental jars quite big (200 c.c.), and because some $\mathrm{CO}_{2}$ went out when the jars were opened and fresh fish introduced, no appreciable change in $\mathrm{pH}$ was noticed during the duration of the series detailed in the tables.

The problem was tackled by another method as well. As will be evident from Table 2, stickles when put in water at $\mathrm{pH} 3$ and having 6.5 c.c. of $\mathrm{O}_{2}$ per litre die within $40-45$ minutes, leaving about $5 \cdot 8$ c.c. per litre of oxygen - a concentration below which, according to Powers' interpretations, stickles should not be able to absorb oxygen at this 
$\mathrm{pH}$. But when these fish were actually introduced in water of this $\mathrm{pH}$ and having as low a concentration of $\mathrm{O}_{2}$ as 1.36 c.c. per litre, they lived almost as long as in the above water (Table 3). These experiments were repeated with even lower concentrations of oxygen, the fish lived about the same time unless the $\mathrm{pH}$ was lower (Table 4).

The ordinary suction pump was employed for reducing the amount of oxygen.

Thirdly, several $\mathrm{pH}$ ranges were prepared by adding $\mathrm{HCl}$ to waters having different amounts of dissolved oxygen. An examination of Table 5 will show that in each range the fish die leaving absolutely different amounts of oxygen. If the ability to extract oxygen at any $\mathrm{pH}$ depends upon the amount of $\mathrm{O}_{2}$ present, then at a particular $\mathrm{pH}$ the individuals in the different ranges should leave almost the same amount of oxygen at their death.

It is interesting to add that in all the above-mentioned experiments the fish of the different ages behaved similarly, except very tiny ones (below $0.15 \mathrm{gm}$.), or those which were ready to breed (above $1.8 \mathrm{gm}$.) see the weight columns in the different tables.

It may be pointed out, however, that the amount of oxygen which the fish absorb per hour per unit weight is not the same at different hydrogen ion concentrations. For instance, at a $\mathrm{pH}$ like 3 it is much less than at $\mathrm{pH}$ 7. This suggests that the hydrogen ions kill the fish by interfering with the respiratory system. But what the above-described experiments establish is that this interference is independent of the amount of oxygen present in the surrounding medium, unless its concentration goes down to $0 \cdot 30-0 \cdot 50$ c.c. per litre, when the fish die of asphyxiation at any $\mathrm{pH}$.

Incidentally, the above experiments suggest that in ponds and rivers where the oxygen content seldom goes down to such a low concentration as $0 \cdot 30$ c.c. per litre, fishes should not, as a rule, die of lack of oxygen, and that therefore other factors, e.g. $\mathrm{pH}, \mathrm{CO}_{2}$ pressure, poisons, etc., have more important ecological bearing than the amount of dissolved oxygen.

It is with great pleasure that I take this opportunity of thanking Dr. E. J. Allen, the Director of the Plymouth Laboratory, and Dr. W. R. G. Atkins, the head of the Physiological Department, who took a keen interest in this investigation, placed all facilities at my disposal and extended numerous courtesies during my stay at Plymouth. 
TABLe 1.

$\mathrm{pH} 3 \cdot 1, \mathrm{O}_{2}$ at start $6 \cdot 5$ c.c. per litre.

\begin{tabular}{|c|c|c|c|c|c|c|c|c|c|c|c|c|}
\hline & \multicolumn{2}{|c|}{ I. } & \multicolumn{2}{|c|}{ II. } & \multicolumn{2}{|c|}{ III. } & \multicolumn{2}{|c|}{ IV. } & \multicolumn{2}{|c|}{ V. } & & \\
\hline 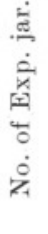 & 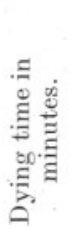 & 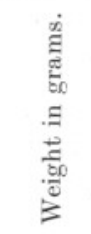 & 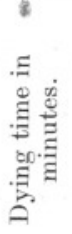 & 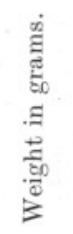 & 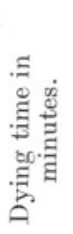 & 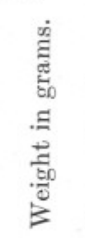 & 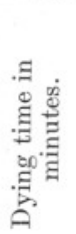 & 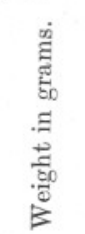 & 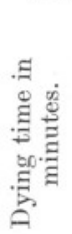 & 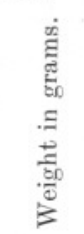 & 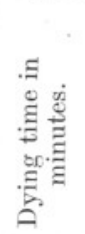 & 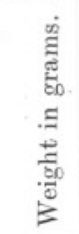 \\
\hline 1 & 38 & $0 \cdot 32$ & 35 & $\cdot 27$ & 42 & $0 \cdot 21$ & 35 & $0 \cdot 23$ & 40 & $0 \cdot 20$ & 34 & $0 \cdot 25$ \\
\hline 2 & 32 & 0.35 & & & & & & & & & & \\
\hline 3 & 31 & $0 \cdot 22$ & 35 & $\cdot 21$ & & & & & & & & \\
\hline 4 & 65 & $1 \cdot 22$ & 58 & $\cdot 25$ & 60 & $0 \cdot 23$ & 60 & $0 \cdot 20$ & 65 & $0 \cdot 20$ & 67 & $1 \cdot 00$ \\
\hline 5 & 47 & $0 \cdot 28$ & 48 & $\cdot 3$ & & . & & & & & & \\
\hline 6 & 60 & $0 \cdot 20$ & & & & & & & & & & \\
\hline 7 & 80 & $0 \cdot 21$ & 78 & $\cdot 2$ & 70 & $0 \cdot 2$ & 75 & $0 \cdot 2$ & 65 & $0 \cdot 18$ & & \\
\hline 8 & 45 & $0 \cdot 20$ & 50 & $\cdot 29$ & 51 & $0 \cdot 23$ & & & & & & \\
\hline & & & 51 & & 56 & & 57 & & 57 & & 51 & \\
\hline
\end{tabular}

$\mathrm{O}_{2}$ at the end of $\mathrm{I}$ lot $5 \cdot 85$ c.c. per litre (Nos. 2 and 6$)$.

\begin{tabular}{|c|c|c|c|c|c|c|}
\hline , & , & II & $5 \cdot 2$ & , & : & (Nos. 3 and 5). \\
\hline ", & , & III & $4 \cdot 8$ & " & ", & (No. 8). \\
\hline ," & : & $\mathrm{V}$ & $4 \cdot 0$ & , & , & (No. 7). \\
\hline ., & & VI & $3 \cdot 5$ & $\therefore$ & , & (Nos. 1 and 4). \\
\hline
\end{tabular}


Table 2.

$\mathrm{pH} 3 \cdot 0, \mathrm{O}_{2} 6 \cdot 5$ c.c. per litre.

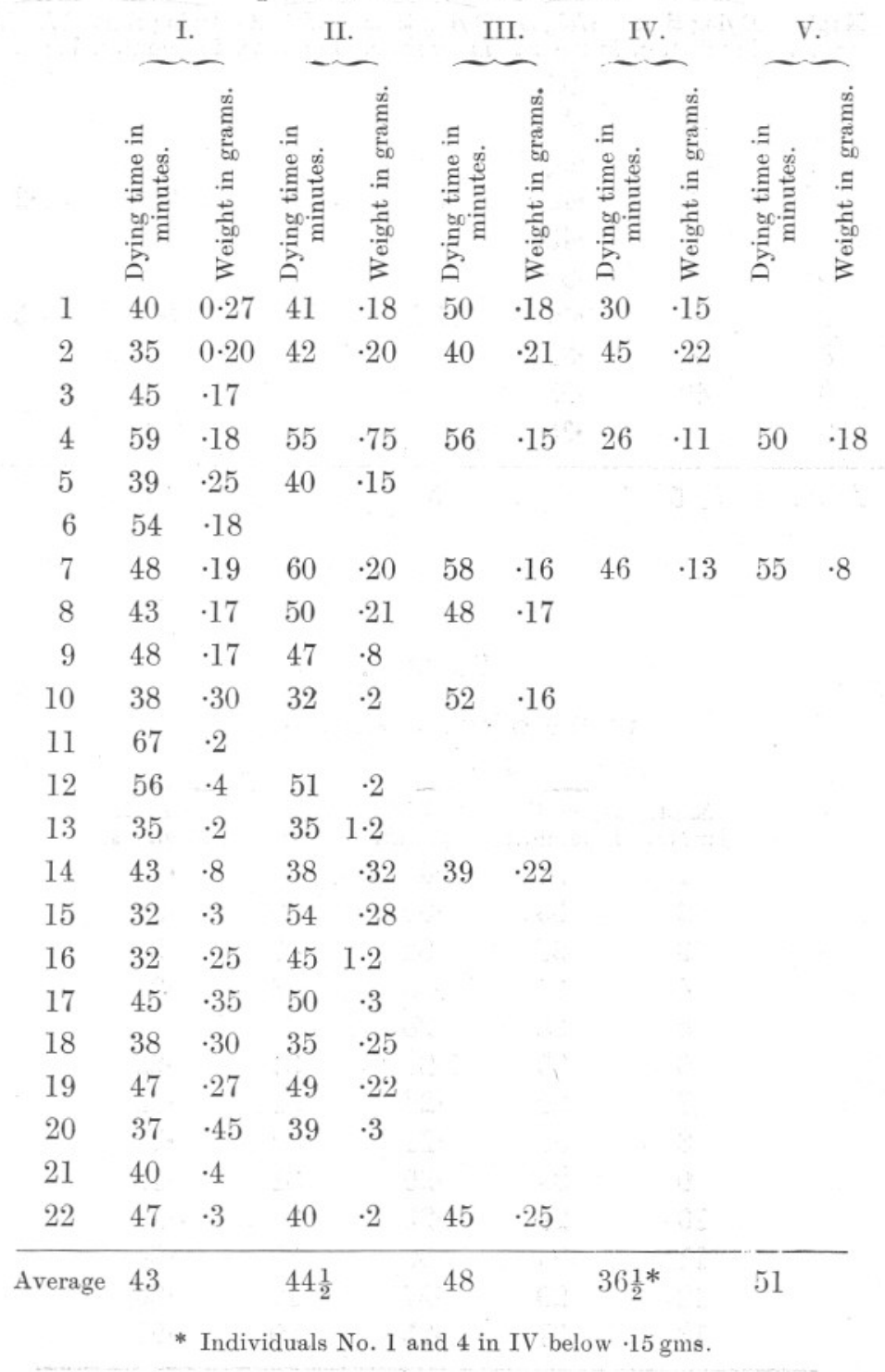


TABLe 3 .

$\mathrm{pH} 3 \cdot 0$, oxygen at start $1 \cdot 36$ c.c. per litre.

I.

II

III.

Expt. Dying time Weight Dying time Weight Dying time Weight jar No. in minutes. in grams. in minutes. in grams. in minutes. in grams

$\begin{array}{rrrrrrr}1 & 35 & \cdot 35 & 30 & 1 \cdot 0 & 34 & 1 \cdot 3 \\ 2 & 35 & \cdot 40 & & & & \\ 3 & 39 & \cdot 45 & & & & \\ 4 & 52 & \cdot 45 & 39 & 1 \cdot 1 & 38 & 1 \cdot 2 \\ 5 & 33 & \cdot 45 & & & & \\ 6 & 37 & \cdot 30 & & & & \\ 7 & 37 & \cdot 40 & 36 & 1 \cdot 8 & 39 & 1 \cdot 5 \\ 8 & 36 & \cdot 32 & & & & \\ 9 & 40 & \cdot 35 & & & & \\ 10 & 50 & \cdot 35 & & & & \end{array}$

Average $\quad 39 \cdot 5$

35

37

Table 4.

$\mathrm{pH} 2 \cdot 9$, oxygen at start $1 \cdot 4$ c.c.

I.

II.

Expt. Dying time Weight Dying time Weight jar No. in minutes. in grams. in minutes. in grams.

\begin{tabular}{rrrrr}
1 & 27 & $\cdot 4$ & 31 & $\cdot 30$ \\
2 & 39 & $\cdot 35$ & 43 & $\cdot 25$ \\
3 & 25 & $\cdot 35$ & 45 & $\cdot 25$ \\
4 & 37 & $\cdot 30$ & 33 & $\cdot 30$ \\
5 & 36 & $\cdot 25$ & & \\
6 & 35 & $1 \cdot 20$ & 34 & $\cdot 22$ \\
7 & 30 & $\cdot 27$ & 31 & $\cdot 25$ \\
8 & 30 & $\cdot 25$ & 30 & $\cdot 17$ \\
9 & 30 & $\cdot 25$ & 31 & $\cdot 18$ \\
10 & 29 & $\cdot 25$ & 30 & $\cdot 20$ \\
11 & 30 & $\cdot 30$ & 30 & $\cdot 20$ \\
12 & 29 & $\cdot 27$ & 17 & $\cdot 20$ \\
13 & 31 & $\cdot 25$ & 29 & $\cdot 20$ \\
\hline Average & 30 & & 29 &
\end{tabular}


Table 5.

\begin{tabular}{|c|c|c|c|c|c|c|c|}
\hline \multirow{2}{*}{$\begin{array}{l}\text { Expt. No. } \\
\text { and } \\
\text { amount of } \\
\text { oxygen } \\
\text { at start. }\end{array}$} & \multicolumn{4}{|c|}{ Low Oxygen Concentration. } & \multicolumn{3}{|c|}{$\begin{array}{l}\text { Control-Oxygen } 6 \cdot 5-7 \mathrm{cc} \text {. } \\
\text { per litre. }\end{array}$} \\
\hline & $\mathrm{pH}$. & $\begin{array}{c}\text { Oxygen } \\
\text { left } \\
\text { at death. }\end{array}$ & $\begin{array}{l}\text { Dying time } \\
\text { in minutes. }\end{array}$ & $\begin{array}{c}\text { Size- } \\
\text { weight } \\
\text { in grams. }\end{array}$ & $\begin{array}{l}\text { Oxygen } \\
\text { left I I } \\
\text { at death. }\end{array}$ & $\begin{array}{c}\text { per litre. } \\
\text { Dying time } \\
\text { in minutes. }\end{array}$ & $\begin{array}{c}\text { Size- } \\
\text { weight } \\
\text { in grams. }\end{array}$ \\
\hline I & $3 \cdot 3$ & $1 \cdot 6$ & 45 & $0 \cdot 50$ & $5 \cdot 5$ & 45 & $0 \cdot 50$ \\
\hline Oxygen & $3 \cdot 0$ & $2 \cdot 7$ & 30 & $0 \cdot 50$ & $6 \cdot 0$ & 29 & $0 \cdot 50$ \\
\hline $\begin{array}{l}3 \cdot 0 \text { c.c. } \\
\text { per litre. }\end{array}$ & $2 \cdot 9$ & $2 \cdot 8$ & 30 & $0 \cdot 50$ & $6 \cdot 24$ & 30 & $0 \cdot 50$ \\
\hline II & $3 \cdot 1$ & $2 \cdot 20$ & 37 & $0 \cdot 20$ & $6 \cdot 4$ & 40 & $0 \cdot 20$ \\
\hline Oxygen & $2 \cdot 9$ & $2 \cdot 25$ & 33 & $0 \cdot 20$ & $6 \cdot 4$ & 35 & $0 \cdot 20$ \\
\hline $2 \cdot 50$ c.c. & $2 \cdot 7$ & $2 \cdot 32$ & 20 & $0 \cdot 20$ & $6 \cdot 4$ & 30 & $0 \cdot 20$ \\
\hline per litre. & $2 \cdot 5$ & $2 \cdot 40$ & 30 & $0 \cdot 20$ & $6 \cdot 5$ & 30 & $0 \cdot 20$ \\
\hline & $2 \cdot 4$ & $2 \cdot 42$ & 25 & $0 \cdot 20$ & $6 \cdot 6$ & 32 & $0 \cdot 25$ \\
\hline . III & $5 \cdot 2$ & $1 \cdot 20$ & 480 & $0 \cdot 30$ & $3 \cdot 28$ & 500 & $0 \cdot 40$ \\
\hline Oxygen & $3 \cdot 9$ & $1 \cdot 40$ & 270 & $0 \cdot 30$ & $4 \cdot 4$ & 245 & $0 \cdot 30$ \\
\hline $\begin{array}{l}2 \cdot 0 \text { c.c. } \\
\text { per litre. }\end{array}$ & $3 \cdot 6$ & 1.52 & 360 & $0 \cdot 25$ & $4 \cdot 8$ & 150 & $0 \cdot 20$ \\
\hline IV & $3 \cdot 1$ & 0.96 & 46 & $0 \cdot 20$ & $5 \cdot 00$ & 48 & .25 \\
\hline Oxygen & $3 \cdot 0$ & $1 \cdot 00$ & 40 & $0 \cdot 20$ & $5 \cdot 36$ & 35 & $\cdot 20$ \\
\hline $\begin{array}{l}1.50 \text { c.c. } \\
\text { per litre. }\end{array}$ & $2 \cdot 9$ & $1 \cdot 04$ & 32 & $0 \cdot 20$ & $6 \cdot 08$ & 40 & $\cdot 20$ \\
\hline V & $3 \cdot 7$ & $1 \cdot 04$ & 82 & $0 \cdot 25$ & $4 \cdot 24$ & 150 & $0 \cdot 22$ \\
\hline Oxygen & $3 \cdot 4$ & $1 \cdot 20$ & 75 & $0 \cdot 30$ & $4 \cdot 70$ & 80 & $0 \cdot 23$ \\
\hline $\begin{array}{l}1.75 \text { c.c. } \\
\text { per litre. }\end{array}$ & $3 \cdot 15$ & $1 \cdot 56$ & 55 & $0 \cdot 22$ & $5 \cdot 04$ & 55 & $2 \cdot 5$ \\
\hline
\end{tabular}


